\title{
Rox Index as Predictor of Ventilatory Failure in Patients Admitted to ICU July 2020 to January 2021
}

\author{
Dulcey Luis*, Caltagirone Raimondo, Sampayo Jose, Pineda Jonathan, Castro John and Cazorla \\ Camilo
}

Internal Medicine University of Los Andes Mérida Venezuela, Venezuela

*Corresponding author: Dulcey Luis, Internal Medicine University of Los Andes Mérida Venezuela, Venezuela

\section{ARTICLE INFO}

Received: 蔧 July 10, 2021

Published: 慧 July 19, 2021

Citation: Dulcey Luis, Caltagirone Raimondo, Sampayo Jose, Pineda Jonathan, Castro John, Cazorla Camilo. Rox Index as Predictor of Ventilatory Failure in Patients Admitted to ICU July 2020 to January 2021. Biomed J Sci \& Tech Res 37(2)-2021. BJSTR. MS.ID.005979.

Keywords: Pneumonia; Risk; Mechanical ventilation; Respiration; Stratification

\begin{abstract}
Introduction: The use of the ROX index in COVID 19 patients allows evaluating those with high risk of ventilatory failure, however it has not been openly validated in patients using non-rebreathing mask.

Objectives: To evaluate the predictive value of the ROX index in patients admitted to the emergency room in July 2020 to January 2021.

Methodology: a retrospective study of 306 adults infected with SARS COV2 through antigenic or molecular testing. The risk score was examined at $2 \mathrm{~h}$ and $12 \mathrm{~h}$ after admission to intensive care.

Results: There was a greater frequency of the male gender $78 \%$ in relation to the female $22 \%$, the values of the ROX index were higher in the group of survivors at $2 \mathrm{~h} 5.8$ ( 4.7 - 6.9), in relation to the deceased $(4.5(3.6-5.6)$. Likewise, at $12 \mathrm{~h}$ the values were higher in the group of survivors 7.8 (5.2 - 8.7) in relation to the deceased (4.9 (3.8 - 6.0). by age and gender, the ROX index was 8.5 at $2 \mathrm{~h}, \mathrm{CI} 2.0-91.4$ ) and at $12 \mathrm{~h}$ was $17.6, \mathrm{CI}$ 2.8 - 93.6. 70 years doubles those under 60 years of age as well as there is a correlation between the older age group and lower ROX indices.
\end{abstract}

Conclusions: The present study showed an adequate correlation between the ROX index, and those patients admitted to intensive care showing higher mortality in those older than 70 years and higher comorbidities index and lower ROX index compared to the other age groups. Are necessary studies with larger groups of patients in order to validate the results found here and thus be able to have tools that allow us to better stratify COVID 19 patients.

\section{Introduction}

Coronavirus disease 2019 (COVID-19) caused by the new severe acute respiratory syndrome coronavirus 2 (SARS-CoV-2) first emerged in China in December 2019 and caused a global pandemic [1]. Approximately $10 \%$ to $20 \%$ of patients admitted to hospital require intensive care, most of whom undergo mechanical ventilation (MV) for pneumonia complicated by severe hypoxemia [2]. The high-flow nasal cannula (HFNC) and continuous positive airway pressure (CPAP) are recognized treatments for hypoxemic respiratory failure caused by community-acquired pneumonia (CAP) [3-7]. HFNC and CPAP may represent definitive therapy that avoids unnecessary MV or provides bridging respiratory support that compensates for the need for immediate MV, preserving finite critical care resources. However, the costs of the system such as HFNC as well as CPAP and the low availability of this in health institutions in developing countries make it necessary to consider the use of other devices such as the non-rebreathing mask in patients who have hypoxemia refractory to low-flow systems. The ratio of the oxygen saturation index (ROX) is used to predict the failure of HFNC in the treatment of CAP [6,7]. There are few published data that describe the use of the ROX index to guide the use of HFNC to treat respiratory failure associated with COVID-19, and there are fewer studies where the system known as the nonrebreathing mask is used; The ROX index was developed as a simple 
bedside test to predict HFNC failure and the need for MV, although it is likely that patients with viral pneumonia were underrepresented in referral and validation studies $[8,9]$.

\section{Objectives}

To evaluate the positive predictive value of the ROX index in patients admitted in the period from July 2020 to January 2021. To determine its power to determine the risk of death and the requirement of invasive mechanical ventilation.

\section{Methodology}

We conducted a retrospective observational study of individuals with laboratory-confirmed COVID-19 through molecular or antigenic tests, which were presented at a health institution in Piedecuesta Santander Colombia between July 2020 and January 2021. Patients who received a mask were identified. no rebreathing, CPAP or VM Tables 1-3. Medical records review captured demographic data and clinical and respiratory parameters. of 405 hospitalized patients with laboratory confirmed COVID-19 during the study period, 306 individuals (306/405, 76\%) admitted to the ICU were eligible for Non-Rebreathing Mask or CPAP as determined by treating physicians according to the national and international guidelines [10]. Of these, 259 people received only a non-rebreathing mask (85\%), 47 (15\%) received a combination with CPAP. The majority of people who received non-rebreathing mask or CPAP experienced severe outcomes, defined as mortality or MV at 30 days of follow-up, for mechanical ventilation (137/306, $45 \%$ ) and for mortality $(96 / 137,70 \%)$. Table 4 in the case of patients who required ventilatory support, in agreement with the findings of multiple studies in this regard in the field of morbidity and mortality. (Figures 1-3) For those admitted, the median of the ROX indices in both deceased and survivors at 2 hours were $(4.5$ (3.6 - 5.6) vs 5.8 ( $4.7-6.9), \mathrm{p}<0.001)$ and the 12 hours (4.9 (3.8 6.0 ) vs 7.8 (5.2 - 8.7), p = <0.001), were significantly lower in the group with severe results. ROX indices adjusted for age and sex below 4.88 at 2 (OR 8.5, CI 2.0 - 91.4) and 12 (OR 17.6, CI 2.8 - 93.6) hours after the start of the non-rebreathing mask the chances of a serious outcome increased.

\section{MANAGEMENT IN ICU COVID 19}

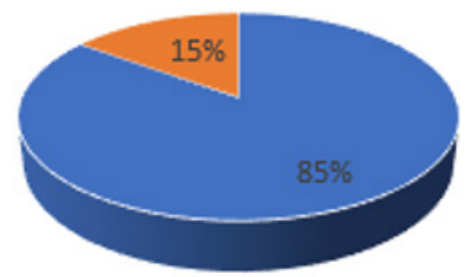

Figure 1: Percentages of use of non-rebreathing mask and CPAP of the patients admitted to the study.

\section{INVASIVE MECHANICAL VENTILATION REQUIREMENT AT 30 DAYS}

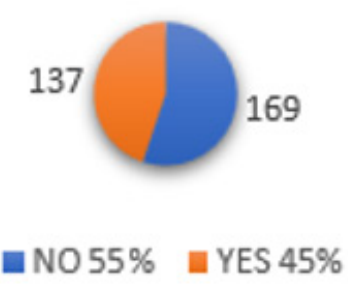

Figure 2: Requirement for invasive ventilatory support in the 30-day follow-up. 


\section{SURVIVAL AND MORTALITY IN PATIENTS (N 96/137) UNDER MECHANICAL VENTILATION AT 30 DAYS}

Figure 3: Requirement for invasive ventilatory support and mortality at 30 days of follow-up

Table 1: Demographic characteristics of the study population and PAFI values at admission.

\begin{tabular}{|c|c|}
\hline Variable & Value \\
\hline Total & 306 \\
\hline Age and median & $59(53-75)$ \\
\hline Gender & Masculino $78 \%$ - Femenino $22 \%$ \\
\hline Charlson Comorbidities Index & $\begin{array}{c}\text { Less of } 1 \text { (n 89, 2 9\%) } \\
\text { Between 1 and 4 (n 167 54\%) } \\
\text { More of 4 (n 51, 17\%) }\end{array}$ \\
\hline PAFI Index & $101.7(65.4-187.3)$ \\
\hline
\end{tabular}

Table 2: Median and standard deviations of the ROX index in deceased and survivors at 2 and $12 \mathrm{~h}$ after admission.

\begin{tabular}{|c|c|c|}
\hline Variable & Supervivientes (Median Y Standar Deviations) & Mortality (Median Y Standar Deviations) \\
\hline ROX at the $2 \mathrm{~h}$ & $5,8(4.7-6.9)$ & $(4,5(3,6-5,6)$ \\
\hline ROX at the $12 \mathrm{~h}$ & $7.8(5.2-8.7)$ & $(4.9(3.8-6.0)$ \\
\hline Statistic Value & $\mathrm{p}<0.001)$ & $\mathrm{p}<0.001)$ \\
\hline
\end{tabular}

Table 3: ROX index adjusted for age and gender at 2 and $12 \mathrm{~h}$ after admission of the patient with its corresponding relative risk.

\begin{tabular}{|c|c|c|}
\hline Variable & Relative Risk & Statistic Analysis \\
\hline ROX at the $2 \mathrm{~h}$ & 8,5, IC $(2,0-91,4)$ & $\mathrm{p}(<0.001)$ \\
\hline ROX at the $12 \mathrm{~h}$ & 17,6, IC $(2,8-93,6$ & $\mathrm{p}(<0.001)$ \\
\hline
\end{tabular}

The ROX Index less than 4.88 at 2 hours after the start of the non-rebreathing mask had the highest positive predictive value for the severe outcome $(97.2 \%$, CI $76.3 \%$ - 98.1\%) of the respiratory variables analyzed. For patients who received a non-rebreathing mask, intubation-free survival was significantly reduced for people with an ROX index less than 4.88 at the time of its calculation $(\mathrm{p}=$ $0.0030)$ and at 2 hours $(p=0.018)$; ). For people who also received CPAP, the ROX index was a strong predictor of complications with a severe outcome, as well as mortality. The use of ROX index on the basis of suitability has been widely used even in high-resource settings $[11,12]$. It is essential to explore the role and results of the non-rebreathing mask and CPAP in the treatment of hypoxemic respiratory failure due to COVID-19 in patients at risk of ventilatory failure. As expected, the people with the highest mortality were older than 70 years compared to those younger than 60 years, $\mathrm{p}>$ 0.001), more fragile and with greater comorbidities Table 5. 
Table 4: Predictive value of ROX at 2 and 12 hours in deceased and survivors.

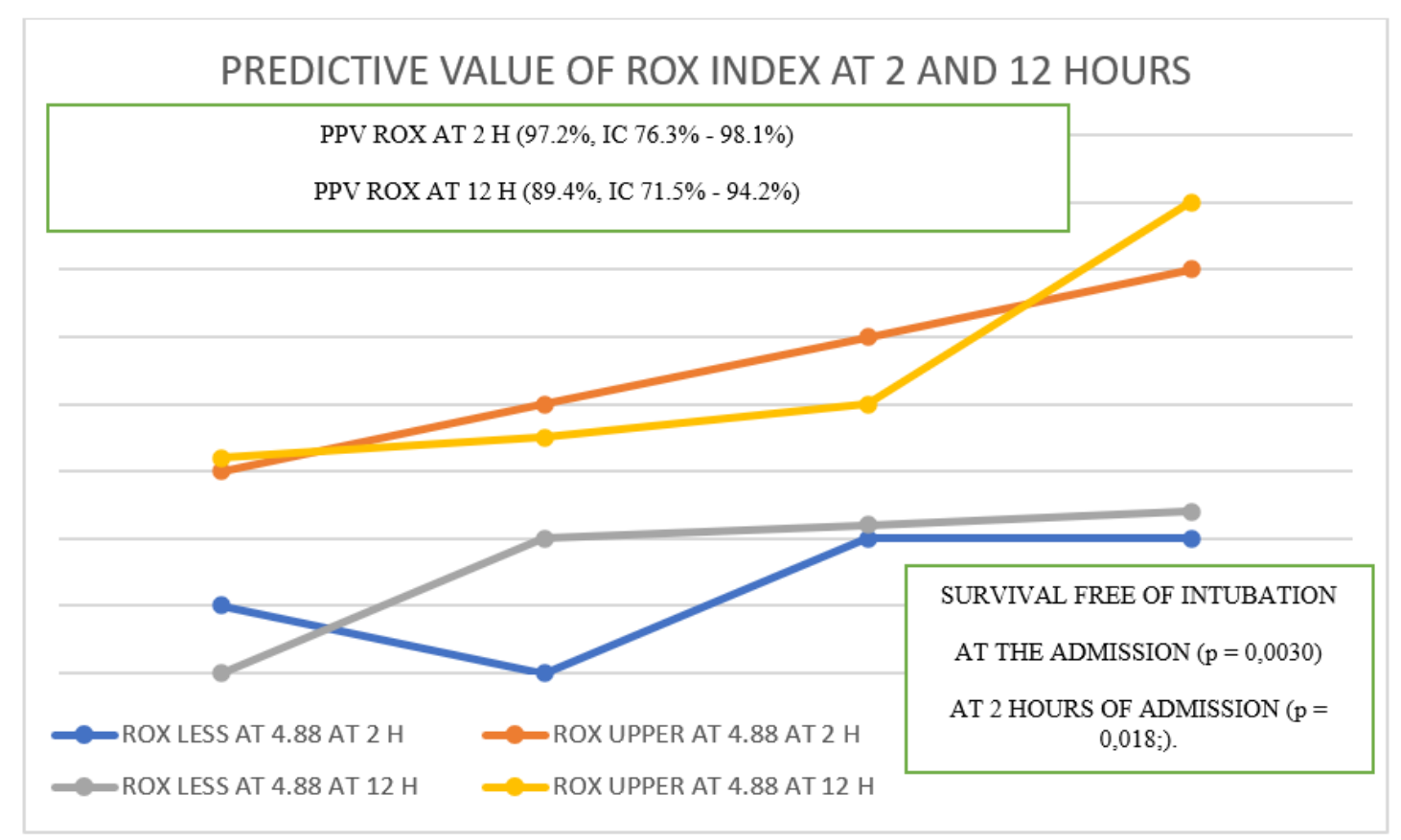

Table 5: Correlation between age groups, ROX index and cumulative mortality of the patients admitted to the study.

\begin{tabular}{|c|c|c|}
\hline Etarial Groups & RoX & Mortality \\
\hline Less of 60 years 148 (48\%) & $4.98(4.62-6.8)$ & $32 \%$ \\
\hline Between 60 and 70 years 117 (38\%) & $4.32(3.8-5.2)$ & $57 \%$ \\
\hline Upper of 70 years 41 (14\%) & $3.88(3.1-4.2)$ & $84 \%$ \\
\hline Statistical Value & $\mathrm{p}>(0,001$ & $\mathrm{p}>0,001$ \\
\hline
\end{tabular}

\section{Conclusion}

The main limitation of our study is its retrospective and singlecenter nature. There were a number of variables improperly recorded in the electronic notes. Clinical observation data is lacking; however, these missing data are clearly highlighted in our summaries and do not preclude analysis. Our study consisted of a male population; a high group of these patients presented a Charlson comorbidities index of between 1 and 4 (n 167 54\%) corresponding to more than half of the sample. It was appreciated that both at admission and at 12 hours the ROX index values were significantly lower in the group with severe results. Most of the people who received non-rebreathing mask or CPAP experienced morbidity and mortality outcomes and complications defined as mortality or ventilatory support at 30 days of follow-up, respectively for mechanical ventilation $(137 / 306,45 \%)$ about half of these patients required it and mortality $(96 / 137,70 \%)$ was higher than two thirds in the case of patients who required ventilatory support, in agreement with the findings of multiple studies in this regard in the field of morbidity and mortality. Our study suggests that the ROX index is a useful predictor of ventilatory failure in COVID-19 respiratory failure to identify early patients likely to require $\mathrm{MV}$, as suggested in previous studies, and warrants prospective validation studies in this setting. The positive predictive value of the ROX index was greater than $85 \%$ to determine negative outcomes, especially when it was less than 4.88 both at 2 and 12 hours after admission. Likewise, the people with the highest mortality were the age group that was over 70 years of age in comparison with those under 60 years of age, $p>0.001$ ), more fragile and with greater comorbidities.

In addition to the scarcity of existing literature where it is proposed to carry out studies in low-resource countries such as ours, expanding even more the total sample, our data suggest the use of the non-rebreathing mask guided by the ROX index in people with predictors of severity. Our study showed that an ROX index lower than 4.88 at 2 and $12 \mathrm{~h}$ showed a high risk of ventilatory failure associated with the requirement of mechanical ventilation, had the highest positive predictive value for the severe outcome (97.2\%, CI 76.3\% - 98.1\%) of the respiratory variables analyzed. Further studies are required to characterize the role of the ROX Index and risk stratification of ventilatory failure to guide resource management and decision making including the exact time to start mechanical ventilation. 


\section{References}

1. Roca O, Messika J, Caralt B, García-de-Acilu M, Sztrymf B, et al. (2016) Predicting success of high-flow nasal cannula in pneumonia patients with hypoxemic respiratory failure: The utility of the ROX index. J Crit Care 35: 200-205.

2. Roca O, Caralt B, Messika J, Samper M, Sztrymf B, et al. (2019) An Index Combining Respiratory Rate and Oxygenation to Predict Outcome of Nasal High-Flow Therapy. Am J Respir Crit Care Med. 199(11): 13681376.

3. Chandel A, Patolia S, Brown AW, Collins AC, Sahjwani D, et al. (2021) King CS High-Flow Nasal Cannula Therapy in COVID-19: Using the ROX Index to Predict Success. Respir Care 66(6): 909-919.

4. Goh KJ, Chai HZ, Ong TH, Sewa DW, Phua GC, et al. (2020) Early prediction of high flow nasal cannula therapy outcomes using a modified ROX index incorporating heart rate. J Intensive Care 8:41.

5. Suliman LA, Abdelgawad TT, Farrag NS, Abdelwahab HW (2021) Validity of ROX index in prediction of risk of intubation in patients with COVID-19 pneumonia. Adv Respir Med 89(1): 1-7.

6. Karim HMR, Esquinas AM (2019) Success or Failure of High-Flow Nasal Oxygen Therapy: The ROX Index Is Good, but a Modified ROX Index May Be Better. Am J Respir Crit Care Med 200(1): 116-117.

\section{ISSN: 2574-1241}

DOI: 10.26717/BJSTR.2021.37.005979

Dulcey Luis. Biomed J Sci \& Tech Res

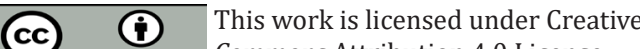

Submission Link: https://biomedres.us/submit-manuscript.php
7. Mauri T, Carlesso E, Spinelli E, Turrini C, Corte FD, et al. (2019) Increasing support by nasal high flow acutely modifies the ROX index in hypoxemic patients: A physiologic study. J Crit Care 53: 183-185.

8. Hill NS, Ruthazer R (2019) Predicting Outcomes of High-Flow Nasal Cannula for Acute Respiratory Distress Syndrome. An Index that ROX. Am J Respir Crit Care Med 199(11): 1300-1302.

9. Ricard JD, Roca O, Lemiale V, Corley A, Braunlich J, et al. (2020) Use of nasal high flow oxygen during acute respiratory failure. Intensive Care Med 46(12): 2238-2247.

10. Lee CU, Jo YH, Lee JH, Kim J, Park SM, et al. (2020) The index of oxygenation to respiratory rate as a prognostic factor for mortality in Sepsis. Am J Emerg Med 24: S0735-6757(20)30849-30844.

11. Panadero C, Abad-Fernández A, Rio-Ramirez MT, Acosta Gutierrez CM, Calderon-Alcala, et al. (2020) High-flow nasal cannula for acute respiratory distress syndrome (ARDS) due to COVID-19. Multidiscip Respir Med 15(1):693.

12. Hu M, Zhou Q, Zheng R, Li X, Ling J, et al. (2020) Application of high-flow nasal cannula in hypoxemic patients with COVID-19: a retrospective cohort study. BMC Pulm Med 20(1): 324.

BIOMEDICAL
RESEARCHES $\quad \begin{aligned} & \text { Assets of Publishing with us } \\ & \text { - Global archiving of articles }\end{aligned}$

